\title{
Front Matter: Volume 8560
}

, "Front Matter: Volume 8560," Proc. SPIE 8560, LED and Display Technologies II, 856001 (18 December 2012); doi: 10.1117/12.2014395

SPIE. Event: Photonics Asia, 2012, Beijing, China 


\title{
PROCEEDINGS OF SPIE
}

\section{LED and Display Technologies II}

\author{
Yanbing Hou \\ Bin Hu \\ Editors
}

\section{5-6 November 2012 Beijing, China}

Sponsored by

SPIE • COS-Chinese Optical Society

\section{Cooperating Organizations}

Tsinghua University (China) • Peking University (China) • Zhejiang University (China) • Beijing Institute of Technology (China) • Beijing University of Posts and Telecommunications (China) • University of Science and Technology of China (China) • Tianjin University (China) • Nankai University (China) • Changchun University of Science and Technology (China) • University of Shanghai for Science and Technology (China) • Capital Normal University (China) • Huazhong University of Science and Technology (China) • Beijing Jiaotong University (China) • Shanghai Institute of Optics and Fine Mechanics (China) • Changchun Institute of Optics and Fine Mechanics (China) • Institute of Semiconductors (China) • Institute of Optics and Electronics (China) • National Univ. of Defense Technology (China) • Institute of Physics (China) • Shanghai Institute of Technical Physics (China) • China Instrument and Control Society (China) • Optoelectronics Technology Committee, COS (China) • SPIE National Committee in China (China) • Japan Optical Society (Japan) • Korea Optical Society (Korea, Republic of) • Australia Optical Society (Australia) • Singapore Optical Society (Singapore)

Supporting Organizations

CAST_China Association for Science and Technology (China) • NSFC—National Nature Science Foundation (China)

Published by

SPIE

\section{Volume 8560}


The papers included in this volume were part of the technical conference cited on the cover and title page. Papers were selected and subject to review by the editors and conference program committee. Some conference presentations may not be available for publication. The papers published in these proceedings reflect the work and thoughts of the authors and are published herein as submitted. The publisher is not responsible for the validity of the information or for any outcomes resulting from reliance thereon.

Please use the following format to cite material from this book:

Author(s), "Title of Paper," in LED and Display Technologies II, edited by Yanbing Hou, Bin Hu, Proceedings of SPIE Vol. 8560 (SPIE, Bellingham, WA, 2012) Article CID Number.

ISSN: 0277-786X

ISBN: 9780819493156

Published by

SPIE

P.O. Box 10, Bellingham, Washington 98227-0010 USA

Telephone +1 3606763290 (Pacific Time) · Fax +1 3606471445

SPIE.org

Copyright (C) 2012, Society of Photo-Optical Instrumentation Engineers.

Copying of material in this book for internal or personal use, or for the internal or personal use of specific clients, beyond the fair use provisions granted by the U.S. Copyright Law is authorized by SPIE subject to payment of copying fees. The Transactional Reporting Service base fee for this volume is $\$ 18.00$ per article (or portion thereof), which should be paid directly to the Copyright Clearance Center (CCC), 222 Rosewood Drive, Danvers, MA 01923. Payment may also be made electronically through CCC Online at copyright.com. Other copying for republication, resale, advertising or promotion, or any form of systematic or multiple reproduction of any material in this book is prohibited except with permission in writing from the publisher. The CCC fee code is $0277-786 \mathrm{X} / 12 / \$ 18.00$.

Printed in the United States of America.

Publication of record for individual papers is online in the SPIE Digital Library.

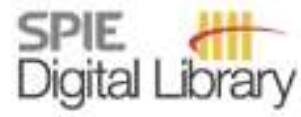

SPIEDigitalLibrary.org

Paper Numbering: Proceedings of SPIE follow an e-First publication model, with papers published first online and then in print and on CD-ROM. Papers are published as they are submitted and meet publication criteria. A unique, consistent, permanent citation identifier (CID) number is assigned to each article at the time of the first publication. Utilization of CIDs allows articles to be fully citable as soon as they are published online, and connects the same identifier to all online, print, and electronic versions of the publication. SPIE uses a six-digit CID article numbering system in which:

- The first four digits correspond to the SPIE volume number.

- The last two digits indicate publication order within the volume using a Base 36 numbering system employing both numerals and letters. These two-number sets start with 00, 01, 02, 03 , $04,05,06,07,08,09,0 A, 0 B \ldots$. 0Z, followed by 10-1Z, 20-2Z, etc.

The CID number appears on each page of the manuscript. The complete citation is used on the first page, and an abbreviated version on subsequent pages. Numbers in the index correspond to the last two digits of the six-digit CID number. 


\section{Contents}

$\vee \quad$ Symposium Committees

vii Conference Committee

ix Quantum dot lasers and relevant nanoheterostructures (Plenary Paper) [8552-1]

A. E. Zhukov, N. V. Kryzhanovskaya, A. V. Savelyev, A. M. Nadtochiy, E. M. Arakcheeva, F. I. Zubov, V. V. Korenev, Saint Petersburg Academic Univ. (Russian Federation);

M. V. Maximov, Y. M. Shernyakov, M. M. Kulagina, I. A. Slovinskiy, loffe Physical-Technical Institute (Russian Federation); D. A. Livshits, Innolume GmbH (Germany); A. Kapsalis,

C. Mesaritakis, D. Syvridis, Univ. of Athens (Greece); A. M. Mintairov, Univ. of Notre Dame (United States)

LED

856005 A simple, low-cost, and portable LED-based multi-wavelength light source for forensic application [8560-4]

W. C. Lee, B. E. Khoo, A. F. Lim bin Abdullah, Univ. Sains Malaysia (Malaysia)

DISPLAY

856008 Improvement of light extraction efficiency of GaN-based flip-chip light-emitting diodes by patterning the double sides of sapphire [8560-9]

X. Du, H. Chen, G. Zhong, X. Dong, W. Chen, X. Lei, X. Liu, Chongqing Univ. (China)

8560 0A Embed a linear irregular Fresnel lens into a simple empty chamber to let a medium or large LED-sourced edge lighting backlight module be thin, lightweight, low-cost, and possess high effect of guiding light rays [8560-7]

W.-G. Chen, Yung Ta Institute of Technology \& Commerce (Taiwan)

8560 OB Design and fabrication of a controllable haze diffuser film [8560-11]

Z. Fang, H. Zhang, X. Zhou, L. Chen, Soochow Univ. (China)

POSTER SESSION

8560 0C The thermal effect of PLEDs by Raman spectra [8560-21]

Z. Qin, J. Wang, Y. Chen, Civil Aviation Univ. of China (China); C. Zhang, Nankai Univ. (China)

$85600 \mathrm{D}$ Effect of the projection lens on speckle contrast measurement in laser projection displays [8560-19]

M. Xu, W. Gao, Y. Shi, P. Zhao, J. Liu, North Univ. of China (China); X. Chen, North Univ. of

China (China) and Vestfold Univ. College (Norway) 
8560 OE Design of freeform LED lens with large light deflection angle for road lighting application [8560-22]

S. Yin, Chongqing Institute of Green and Intelligent Technology (China); Z. Wang, Chongqing Institute of Green and Intelligent Technology (China) and Institute of Optics and Electronics (China); X. Sun, Chongqing Institute of Green and Intelligent Technology (China); L. Xia, Chongqing Institute of Green and Intelligent Technology (China) and Institute of Optics and Electronics (China); H. Pang, Q. Deng, Institute of Optics and Electronics (China); C. Du, Chongqing Institute of Green and Intelligent Technology (China)

$8560 \mathrm{OF}$ Preparation and characterization of $\mathrm{Eu}^{3+}$ ion in $\mathrm{Mg}$-substituted tricalcium phosphate phosphors [8560-24]

T.-Y. Chang, H.-M. Lin, T.-Y. Lin, National Taiwan Ocean Univ. (Taiwan)

$8560 \mathrm{OH} \quad \mathrm{BaAl}_{2} \mathrm{~S} 4: \mathrm{Eu}$ thin films sputtered by complex target with spark plasma sintering BaS:Eu pellets [8560-13]

D. Zhang, Beijing Space Technology Development and Testing Ctr. (China) and Beijing Institute of Technology (China); W. Xue, Z. Yu, Beijing Institute of Technology (China)

$8560 \mathrm{OL} \quad$ A new uniform chromaticity diagram based on CIE1931 (x, y) [8560-17]

Y. Lian, N. Liao, Beijing Institute of Technology (China); J. Liang, Dalian Polytechnic Univ. (China); X. Wang, Information Engineering Univ. of PLA (China); J. Wang, Beijing Institute of Technology (China)

$8560 \mathrm{ON}$ The variation laws of mutual coherence function in laser projector with moving diffuser for speckle reduction [8560-25]

G. Li, Y. Qiu, Y. Zheng, H. Li, Fujian Normal Univ. (China)

856000 Quantum efficiency measurement of luminescence glasses for white LED [8560-20]

X. Dong, X. Du, Y. Liu, L. Ren, L. Jin, X. Lei, W. Chen, Chongqing Univ. (China)

Author Index

iv 


\title{
Symposium Committees
}

\author{
General Chairs \\ Eustace L. Dereniak, College of Optical Sciences, The University of \\ Arizona (United States) \\ Bingkun Zhou, Tsinghua University (China)
}

General Cochairs

Arthur Chiou, National Yang-Ming University (Taiwan, China)

Zhizhan Xu, Shanghai Institute of Optics and Fine Mechanics (China)

Jianlin Cao, China Ministry of Science and Technology (China)

Junhao Chu, Shanghai Institute of Technical Physics (China)

Technical Program Chairs

Songlin Zhuang, Shanghai University of Science and Technology (China)

Xingde Li, Johns Hopkins University (United States)

Technical Program Cochairs

Qiming Wang, Institute of Semiconductors (China)

Xu Liu, Zhejiang University (China)

Daoyin Yu, Tianjin University (China)

Qihuang Gong, Peking University (China)

Tianchu Li, National Institute of Metrology (China)

Wei Huang, Nanjing University of Posts and Telecommunications (China)

Local Organizing Committee Chair

Guangcan Guo, University of Science and Technology of China (China) 
Local Organizing Committee Cochairs

Guoqiang Ni, Beijing Institute of Technology (China)

Shusen Xie, Fujian Normal University (China)

Xiaomin Ren, Beijing University of Posts and Telecommunications (China)

Ying Gu, PLA General Hospital (China)

Huilin Jiang, Changchun University of Science and Technology (China)

General Secretary

Qihuang Gong, Peking University (China)

Local Organizing Committee

Yan Li, Chinese Optical Society/Peking University (China)

Zhiping Zhou, Peking University (China)

Changhe Zhou, Shanghai Institute of Optics and Fine Mechanics (China)

Qingming Luo, Huazhong University of Science and Technology (China)

Chongxiu Yu, Beijing University of Posts and Telecommunications (China)

Hongda Chen, Institute of Semiconductors (China)

Yongtian Wang, Beijing Institute of Technology (China)

Yiping Cui, Southeast University (China)

Xuping Zhang, Nanjing University (China)

Feijun Song, Daheng Corporation (China)

Cunlin Zhang, Capital Normal University (China)

Yanting Lu, Nanjing University (China)

Yuejin Zhao, Beijing Institute of Technology (China)

Chunqing Gao, Beijing Institute of Technology (China)

Tiegen Liu, Tianjin University (China)

Xiaocong Yuan, Nankai University (China)

Weimin Chen, Chongqing University (China)

Zhongwei Fan, Academy of Optoelectronics (China)

Hanyi Zhang, Tsinghua University (China)

Lan Wu, Zhejiang University (China)

Yongsheng Zhang, University of Science and Technology of China (China)

Hong Yang, Peking University (China)

Xiaoying Li, Tianjin University (China)

Lin Zhai, Chinese Optical Society (China) 


\title{
Conference Committee
}

\author{
Conference Chairs
}

Yanbing Hou, Beijing Jiaotong University (China)

Bin Hu, The University of Tennessee (United States)

Conference Program Committee

Donal D. C. Bradley, Imperial College London (United Kingdom)

Youmei Dong, BOE Technology Group Company, Ltd. (China)

Wei Huang, Nanjing University of Posts and Telecommunications (China)

Fengyi Jiang, Lattice Power (Jiangxi) Corporation (China)

Hoi Sing Kwok, Hong Kong University of Science and Technology (Hong Kong, China)

Liang-Sheng Liao, Soochow University (China)

Shi-Yong Liu, Jilin University (China)

Yunqi Liu, Institute of Chemistry (China)

Zhidong Lou, Beijing Jiaotong University (China)

Junbiao Peng, South China University of Technology (China)

Yong Qiu, Tsinghua University (China)

Jun Ruan, China Solid State Lighting Alliance (China)

Xiao Wei Sun, Nanyang Technological University (Singapore)

Baoping Wang, Southeast University (China)

Lixiang Wang, Changchun Institute of Applied Chemistry (China)

Xingwei Wu, iFire Technology Ltd. (Canada)

Zhiguo Xiao, Luming Science and Technology Group (China)

Ningsheng $X_{u}$, Sun Yat-Sen University (China)

Guo-Yi Zhang, Peking University (China)

\section{Session Chairs}

1 LED I

Bin Hu, The University of Tennessee (United States)

2 LED ॥

Bin Hu, The University of Tennessee (United States)

3 Display

Yanbing Hou, Beijing Jiaotong University (China) 
Proc. of SPIE Vol. $8560856001-8$

Downloaded From: https://www.spiedigitallibrary.org/conference-proceedings-of-spie on 26 Apr 2023 Terms of Use: https://www.spiedigitallibrary.org/terms-of-use 